\title{
Análisis comparativo de juntas soldadas mediante el proceso GMAW con técnicas de inspección visual e inspección visual mediante visión artificial
}

\author{
Federico Escorcia-Barrios ${ }^{\mathrm{a}}$, Armando Medina-Cárdenas ${ }^{\mathrm{a}}$, José Cuello-Navarro ${ }^{\mathrm{b}}$, Kevin Velázquez \\ Gutiérrez $^{\mathrm{b}}$, José Escorcia-Gutiérrez ${ }^{\mathrm{b}} \&$ Roosvel Soto-Díaz \\ a Ingeniería Mecánica, Universidad Autónoma del Caribe, Barranquilla, Colombia. \\ federico.escorcia@uac.edu.co, armando.medina@uac.edu.co \\ ${ }^{b}$ Ingeniería Electrónica y Telecomunicaciones, Universidad Autónoma del Caribe, Barranquilla, Colombia. \\ josecnav27@gmail.com,kenygma@gmail.com,jose.escorcia23@gmail.com \\ ${ }^{c}$ Ingeniería Biomédica, Universidad Simón Bolívar, Barranquilla, Colombia, Colombia. \\ roosvel.soto@unisimon.edu.co
}

Recibido: Septiembre 08, 2021.

Recibido en su versión corregida: Octubre 04, 2021.

https://doi.org/10.54606/Sextante2021.v25.03

Aceptación: Octubre 15, 2021.

Cómo citar: Escorcia-Barrios, F., Medina-Cardenas, A., Velázquez Gutierrez, K., Cuello-Navarro, J., Escorcia-Gutiérrez, J. \& SotoDíaz R. (2021). Análisis comparativo de juntas soldadas mediante el proceso GMAW con técnicas de inspección visual e inspección visual mediante visión artificial. Revista Sextante, 25, pp. 19 - 28, 2021.

\section{Resumen}

En este trabajo se realizó un análisis comparativo entre inspección visual (IV) y la inspección visual mediante visión artificial (IVA), para la evaluación de la calidad superficial de uniones soldadas de acero inoxidable austenítico AISI 304, mediante el proceso GMAW. Para determinar los criterios de evaluación se tuvieron en cuenta los códigos AWS D1.6 y guías de inspección AWS parte $\mathrm{B}$, conociéndose así los tipos de discontinuidades y defectos que se pueden presentar en una unión de soldadura, los criterios de aceptación y aplicación de las técnicas de inspección. Posteriormente se diseñaron y generaron muestras soldadas a las cuales se les indujeron discontinuidades y defectos, identificándose como principales el exceso de penetración, falta de penetración, falta de continuidad, porosidad y salpicaduras. Teniendo las placas soldadas se realizó, de manera inicial, la evaluación de estas aplicando técnicas y normas de inspección visual.

En segundo lugar, se implementó el método de evaluación mediante inspección visual y mediante visión artificial (IVA) para las probetas evaluadas anteriormente, a través de inspección visual (IV). Como resultado se realizó el respectivo análisis comparativo de los resultados obtenidos con ambas técnicas y se determinó que las probetas evaluadas por ambos métodos de inspección presentaron resultados similares y confiables, la inspección visual sigue siendo el método tradicional para evaluar la soldadura, sin embargo, la inspección visual mediante visión artificial demostró ser un método novedoso en el que se pudo resaltar de manera más eficiente la identificación de los poros, salpicadura, falta de continuidad y falta de penetración.

Palabras clave: Defectología; Discontinuidades; GMAW; Inspección visual; Procesamiento de imágenes; Visión artificial. 


\title{
Comparative analysis of joints welded using the GMAW process with visual inspection techniques and visual inspection using artificial vision.
}

\begin{abstract}
In this work, a comparative analysis was carried out between visual inspection (IV) and visual inspection by artificial vision (IVA) for the evaluation of the surface quality of welded joints of austenitic stainless steel AISI 304 using the GMAW process. To determine the evaluation criteria, the AWS D1.6 codes and AWS part B inspection guides were taken into account, thus knowing the types of discontinuities and defects that can occur in a weld joint, the acceptance and application criteria of the inspection techniques. Subsequently, welded samples were designed and generated to which discontinuities and defects were induced, identifying as main the excess penetration, lack of penetration, lack of continuity, porosity, and spattering. Having the plates welded, they were initially evaluated by applying visual inspection techniques and standards.

Second, the evaluation method by visual inspection by artificial vision (IVA) was implemented for the specimens previously evaluated by visual inspection (IV). As a result, the respective comparative analysis of the results obtained with both techniques was carried out and it was determined that the specimens evaluated by both inspection methods presented similar and reliable results, visual inspection is still the traditional method to evaluate the weld, however, the Visual inspection by artificial vision proved to be a novel method in which the identification of pores, spatter, lack of continuity and lack of penetration could be highlighted more efficiently.
\end{abstract}

Keywords: Artificial vision; Defectology; Discontinuities; GMAW; Image processing; Visual inspection.

\section{Introducción}

Los aceros inoxidables son aleaciones a base de hierro que contienen al menos $11 \%$ de cromo y hasta $0.8 \%$ de carbono. Algunos grados contienen níquel como segundo elemento de aleación. Cuando el contenido total de la aleación excede aproximadamente el 50\%, la designación "resistente al calor" es más aplicable que inoxidable. Su principal característica es su alta resistencia a la corrosión. Esta resistencia es debido a la formación espontánea de una capa de óxido de cromo en la superficie del acero. Aunque es extremadamente fina, esta película invisible está firmemente adherida al metal y es extremadamente protectora en una amplia gama de medios corrosivos (Indura: Tecnología a su servicio , 2010). La soldadura en aceros inoxidables y en especial en los aceros austeníticos genera grandes cambios en sus propiedades, efecto de la selección del proceso de soldadura, es decir, procesos como el GMAW generan menor afectación en el material. Sin embargo, por tener los aceros inoxidables austeníticos tienen un alto coeficiente de expansión térmica, sobre un $50 \%$ más alto que los aceros al carbono o de aleación de la serie 400, el cual requiere sumo cuidado para disminuir la distorsión, las deformaciones de las partes soldadas y discontinuidades en el cordón y las partes subyacentes a él (Marulanda, Burbano, \& Pelaez, 2013)

Al mismo ritmo que las técnicas de soldadura evolucionan, el control de calidad también lo hace porque la posibilidad de fallas siempre está presente. En el proceso de soldadura ocurre la fusión del metal que se requiere unir y posteriormente se solidifica. Durante el calentamiento y enfriamiento ocurren en diferentes grados estos fenómenos: formación de óxidos, de escorias, precipitación de aleantes, recristalización, entre otros. Todo ello afecta la resistencia mecánica y la resistencia a la corrosión del material que, en principio, se prefiere por ser "inoxidable", pero que es inevitable que sea afectado por el calor propio de la soldadura.

Conocidas las afectaciones de la temperatura en las juntas soldadas, éstas deben ajustarse a los rangos admisibles que son tenidos en cuenta desde el diseño para que se cumplan en la práctica. Algunas variables se controlan directamente al momento de la ejecución de la soldadura, mientras que otras se revisan después de haberse terminado.

El trabajo realizado por Castro \& Serrano (2016), evaluó la influencia del tamaño de las discontinuidades en las propiedades mecánicas de las uniones soldadas bajo norma API 1104 donde el objeto de trabajo fue verificar el alcance de la 
normatividad API respecto a propiedades mecánicas. Mientras que, Trujillo (2017), realizó la evaluación de la soldabilidad del acero inoxidable austenítico AISI 304 desde el punto de vista metalúrgico, donde el objeto de trabajo fue analizar la soldabilidad del acero inoxidable austenítico AISI 304 mediante el proceso GMAW. Lo anterior es evidencia de que se sigue trabajando actualmente en temas entorno a los procesos de soldadura y la evaluación de sus respuestas frente a diversas propiedades. Sin embargo, el punto de partida para todos los procesos de evaluación de juntas soldadas independientemente de la respuesta a evaluar es la inspección visual.

En ambos casos la inspección visual es la base práctica para detectar las fallas evidentes como: grietas, poros y salpicaduras. Aun así, solo la inspección por parte de un personal calificado brinda las garantías mínimas en la práctica; por lo que la pericia, disponibilidad y rapidez del humano resultan un cuello de botella para producciones industriales.

Por su parte, existen suficientes desarrollos teóricos y experiencias documentadas donde la captura de imágenes y sus análisis asistidos por computador resultan una técnica que incrementa la productividad, la calidad y la seguridad de los procesos de fabricación (Hurtado \& Vaca, 2021). Se utiliza especialmente en el control de calidad, la manipulación de materiales, la ordenación por calidades (grading), la prueba y la calibración de aparatos y la monitorización de procesos implementados (Vargas, 2010). Carbajal (2017), realizó una inspección visual remota en juntas soldadas de tuberías de acero inoxidable mayores a 4in de diámetro y con espesores hasta $3 \mathrm{~mm}$.

Teniendo en cuenta lo anterior, elaboró un procedimiento para la inspección visual remota en juntas soldadas de 2 prototipos, uno sin purga de gas argón, que permitió capturar imagen patrón de la oxidación de la unión soldada al interior de la tubería y un segundo prototipo con previa purga de gas argón, que permitió demostrar que es indispensable purgar las tuberías de acero inoxidable para garantizar la sanidad de la junta soldada. Obteniendo así, las imágenes patrones de las principales discontinuidades que se pueden presentar en el interior de una tubería donde se verificó la importancia de purgar con argón la junta que se va a soldar, ya que sin ella se oxidará toda la unión soldada, algo que la norma AWS D18.1 no acepta.

Por otra parte, uno de estos desarrollos fue el realizado por Loja (2015), que en su trabajo de investigación realizó la inspección de soldaduras MIG/MAG en piezas metálicas, utilizando técnicas de visión artificial y procesamiento de imágenes. El objeto de trabajo del investigador fue implementar el sistema de inspección visual estructural y hardware en diferentes tipos de soldaduras. Con el fin de detectar fallas de los tipos: porosidad, salpicaduras y discontinuidad de la soldadura, se creó un sistema de visión artificial que hace relación con la inspección visual en estructuras soldadas por medio de diferentes procesos de soldadura que contaba con cámaras web y almacenamientos de grandes escalas para el desarrollo de una interfaz gráfica y poder interpretar el desarrollo de resultados de la inspección visual.

La visión artificial y el procesamiento de imágenes tienen un alto impacto en las aplicaciones industriales y no industriales en las que una combinación de hardware y software proporciona orientación a diversos dispositivos, por medio de la captura y el procesamiento de imágenes, tanto en el campo de reconocimiento de objetos como en el de inspección y control de calidad de un suministro en donde se necesita un sistema óptimo y confiable (COGNEX, 2018; Loja, 2015). Esta herramienta en los procesos de soldadura permite inspeccionar $\mathrm{y}$ detectar discontinuidades, llegando a ser un apoyo para la inspección visual realizada por el hombre, ya que se podrían realizar mediciones cuantitativas y cualitativas.

El objeto de este artículo es analizar el aspecto de discontinuidades y defectología (porosidad, penetración incompleta, penetración excesiva, falta de continuidad y salpicadura), que se pueden presentar en uniones soldadas, analizadas con visión artificial y realizar comparación con técnicas de inspección visual basándose en los criterios de aceptación de los códigos AWS D1.6 y AWS B1.11 (AWS, 2007). Como objetivo planteamos determinar la confiabilidad de la inspección visual y visión artificial bidimensional aplicada en la evaluación de la calidad superficial de juntas soldadas por GMAW en probetas de AISI304. 
El artículo se encuentra organizado de la siguiente manera: se exponen en la sección 2 los materiales y métodos desarrollados para la consecución de resultados. De acuerdo con los materiales y métodos propuestos se plantea la sección 3, que pertenece a los resultados $\mathrm{y}$ discusión. Finalmente, en la sección 4 se exponen las conclusiones del artículo.

\section{Materiales y métodos}

\subsection{Materiales}

El metal base utilizado durante el proceso de soldadura fue un acero inoxidable austenítico AISI 304L con unas dimensiones de $160 \mathrm{~mm} \times 80 \mathrm{~mm} \times 3 \mathrm{~mm}$ y una composición química como se describe en la Tabla 1. El metal de aporte utilizado fue un alambre MIG ER308L, compatible con el metal base y su composición química como se muestra en la Tabla 2.

\subsection{Proceso y procedimiento de soldadura}

El proceso de soldadura realizado para el desarrollo de las juntas fue el proceso GMAW. Se utilizó el aporte ER 308L que presenta características similares al metal base, como se muestra en las Tablas 1 y $\underline{2}$. Por otra parte, el gas implementado durante el proceso de soldadura fue el Cryomig, que consta de $2 \%$ de oxígeno y $98 \%$ de argón. La preparación de las juntas se basó en la norma AWS D1.6 (AWS, 2007), donde se estableció una junta a tope sin bisel como se muestra en la Figura 1. El equipo utilizado en la fabricación de las juntas soldadas fue una máquina de soldar Lincoln MIG WELD 260-D.

Los parámetros se basaron de acuerdo con el procedimiento de soldadura diseñado bajo un WPS, con el cual se indujeron discontinuidades para la

Tabla 1. Composición química de AISI 304L.

\begin{tabular}{ccccccc}
\hline Elemento & $\boldsymbol{C}$ & $\boldsymbol{C r}$ & $\boldsymbol{N i}$ & $\boldsymbol{S}$ & $\boldsymbol{M n}$ & $\boldsymbol{S i}$ \\
\hline$\%$ & $<0.03$ & $18-20$ & $8-12$ & 0.03 & $<2.0$ & $<1.0$
\end{tabular}

Fuente: Los autores.

Tabla 2. Composición química alambre MIG ER308L.

\begin{tabular}{cccccccc}
\hline Elemento & $\boldsymbol{C}$ & $\boldsymbol{C r}$ & $\boldsymbol{N i}$ & $\boldsymbol{S}$ & $\mathbf{M n}$ & $\boldsymbol{S i}$ & $\boldsymbol{M o}$ \\
\hline$\%$ & $<0.03$ & $18-20$ & $8-12$ & 0.03 & $<2.0$ & $<1.0$ & 0.19
\end{tabular}

Fuente: Los autores. comparación en los resultados frente soldaduras sanas. Los defectos que se indujeron fueron controlados por las variables operativas durante el proceso, como lo fueron voltaje, corriente, velocidad de aporte y presión del gas protector.

\subsection{Inspección visual (IV)}

La inspección visual se realizó utilizando un kit de herramientas básicas de la práctica como son: calibrador, flexómetro, lupa de lente convexo y kit de galgas marca G.A.L GAGE CO como se muestra en la Figura 2.

Se aplicó la inspección visual como primer método para examinar las superficies de las placas soldadas y verificar que cumplan con las condiciones de calidad especificadas, por lo cual se revisó, teniendo en cuenta las Normas AWS B1.10 Guía para exámenes no destructivos de soldadura, AWS B1.11 Guía para examen visual de soldaduras.

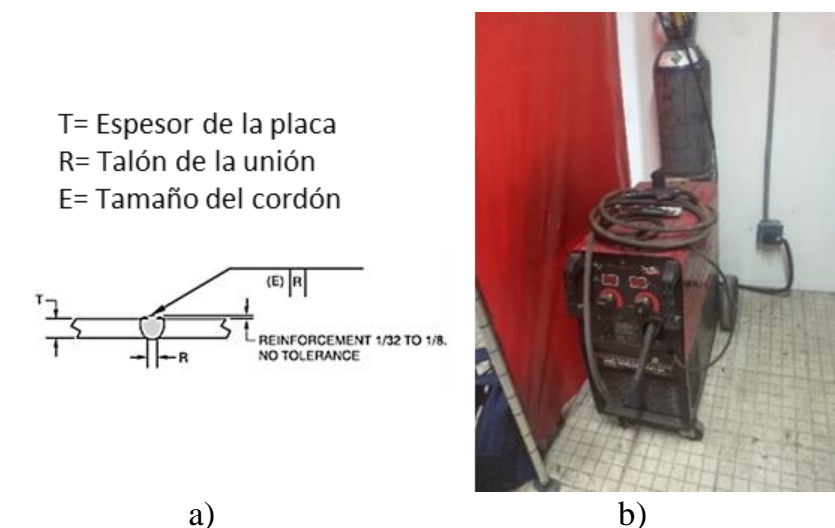

Figura 1. (a) Diseño de junta y (b) Maquina Lincoln MIG WELD 260-D.

Fuente: Los autores.

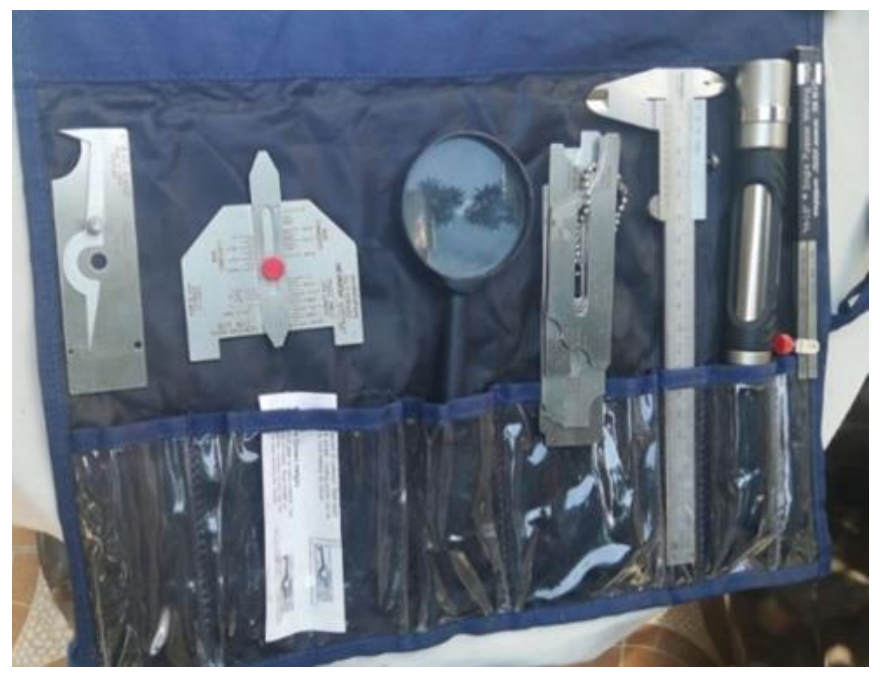

Figura 2. Kit de herramientas para la inspección visual.

Fuente: Los autores. 
Adicionalmente, se tuvo en cuenta la norma AWS D1.6 Soldadura estructural de aceros inoxidables en la cual se establecen los criterios de aceptación para la inspección visual en uniones soldadas de acero inoxidable y los valores máximos permisibles para algunas discontinuidades. Obteniendo así los conocimientos específicos para realizar la inspección de las probetas soldadas y determinar si es aceptable o no. Para diferenciar las discontinuidades presentadas en el proceso de soldadura se denominaron de la siguiente forma:

- $\quad P$ : Porosidad.

- $F C$ : Falta de continuidad.

- $\quad S A$ : Salpicadura.

- $\quad F P:$ Falta de penetración.

- $\quad E P$ : Exceso de penetración.

\subsection{Inspección por visión artificial (IVA)}

Para la inspección visual (ver Figura 3) se realizó el procesamiento de imágenes tomadas a través de una cámara Logitech C525 y Nikon Coolpix S2900. La inspección de las probetas por visión artificial fue originada en diferentes tamaños como son en posición horizontal y vertical con medidas $640 \mathrm{X} 480$ y 1280X90. Finalmente, se realizó la adquisición de imágenes mediante un cable. Se controló la toma de fotografías por medio de un cable USB que cargaba una base de datos programada en MATLAB para generar el entrenamiento artificial con una aplicación de línea denominada LabelBox. El conjunto de datos se fraccionó en dos partes, el $70 \%$ de los datos fueron usados para la validación del sistema y el $30 \%$ restante para el entrenamiento del software de inspección.

Las imágenes fueron analizadas mediante diferentes procesos de adecuación como recorte de la imagen (con el fin de analizar solo la región real del cordón), se llevó la imagen al espacio de color CMY (para definir el cordón de soldadura y el metal base), culminando con la separación del cordón del metal base. Finalmente, se realizó la detección del contorno del cordón de soldadura y las discontinuidades presentes en la imagen, siendo separadas en imágenes binarias y por último se combinó en el espacio de color RGB asignando un color específico a cada discontinuidad.

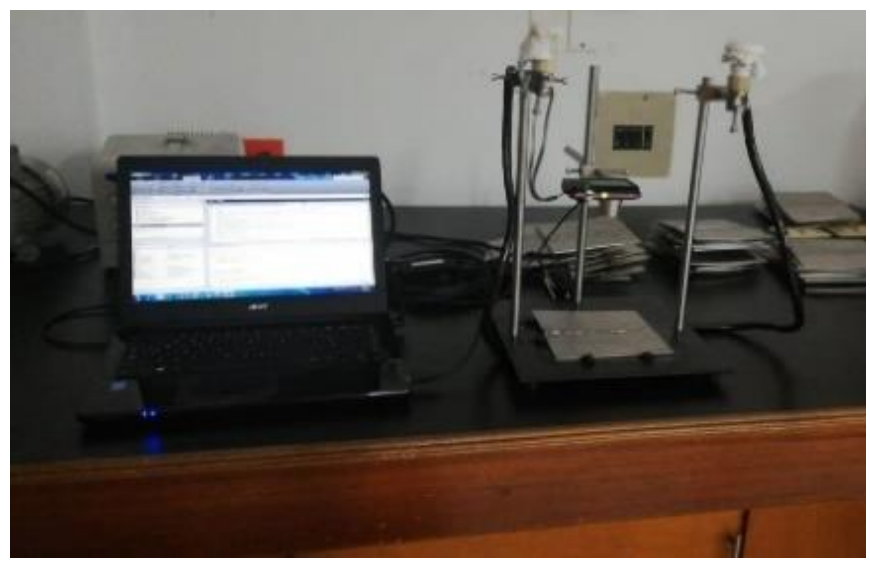

Figura 3. Dispositivo de inspección por visión artificial. Fuente: Los autores.
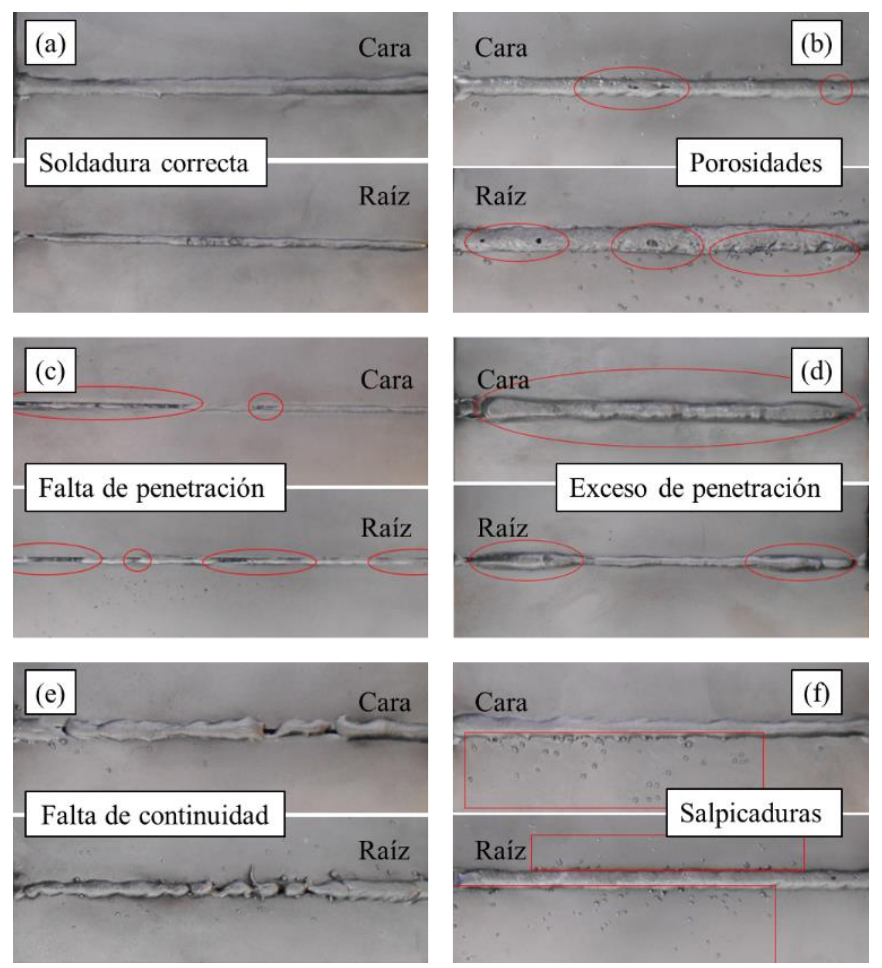

Figura 4. Productos soldados con las discontinuidades seleccionadas.

Fuente: Los autores.

\section{Resultados y discusión}

\subsection{Discontinuidades y defectos}

Para la obtención de las distintas discontinuidades de las soldaduras se realizaron cambios en algunas de las variables y parámetros durante el proceso GMAW. Dichas variables alteradas fueron: corriente, velocidad de aporte, interrupción o disminución en el flujo del gas de protección y técnicas inadecuadas de soldadura. Lo anterior se puede evidenciar en la Figura 4. Donde se muestra la inducción de las diversas discontinuidades en juntas soldadas. 
En la en la sección (a) de la Figura 4 se evidencia una soldadura libre de defectos, donde las variables operativas y técnicas estuvieron controladas de manera ideal para la obtención de un cordón regular en cara y raíz. En la sección (b) se evidencia la porosidad, como cavidades formadas en la superficie de cordón de soldadura inducidas mediante la interrupción y/o se disminución del flujo de gas de protección. En la sección (c) se evidencia la falta de penetración como aquellas zonas en la raíz, en las que la soldadura no alcanzó a fundir los bordes y tampoco logró alcanzar una altura mayor que sobresaliera del borde de la junta, las cuales fueron inducidas por utilizar velocidad de avance excesivo, poca separación en la raíz o técnicas inadecuadas de soldadura. En la sección (d) se evidencia el exceso de penetración como el exceso de metal de soldadura depositado en la cara de la raíz donde su altura y tamaño pueden llegar a ser mayores a los permitidos por un código, inducidas por utilizar velocidad de avance muy lenta, por técnicas inadecuadas de soldadura y/o voltaje y corrientes elevadas. En la sección (e) se evidencia la falta de continuidad como cordones irregulares, con mal aspecto, interrupción del cordón de soldadura, mala reanudación y falta de fusión de los bordes; y fueron inducidas por no mantener una velocidad de avance constante, técnicas de aplicación inadecuadas y/o variación de parámetros de soldadura. En la sección (f) se evidencian las salpicaduras como partículas esféricas metálicas adheridas al metal base de forma dispersas y fueron generaron por un stick out largo, y parámetros de soldaduras en relación voltajealimentación de alambre inadecuados. Dichos resultados son relacionables con los obtenidos por Gámez, (2017).

\subsection{Inspección visual (IV)}

Posterior al análisis de las discontinuidades se realizó la inspección visual utilizando las herramientas de medición y basándose en los criterios de aceptación del código AWS D1.6 2017, para determinar si eran aceptables o rechazadas las juntas soldadas a evaluar. La Figura 5 presenta la inspección visual (IV) para cada junta soldada con los defectos realizados y la codificación de cada una. Basados en la norma AWS D1.6 se realizó un informe de inspección visual el cual dio como resultado el siguiente análisis:
- Junta soldada P25: se observó una junta soldada con la longitud y tamaño apropiados. No se observan indicaciones superficiales relevantes. Aceptable.

- Junta soldada P95: Se observa falta de penetración y fusión incompleta en bordes de la raíz. Indicaciones no aceptables por el código. $\underline{\text { Rechazada. }}$

- Junta soldada P33: Refuerzo de raíz mayor a $3 \mathrm{~mm}$. Indicación no aceptable por el código. $\underline{\text { Rechazada. }}$

- Junta soldada P46: Se observan poros en la superficie de soldadura que su suma excede $3 / 8$ en pulgada lineal. Indicación no aceptable por el código. Rechazada.

- Junta soldada P99: Múltiples indicaciones que no son aceptadas por el código. Rechazada.

- Junta soldada P101: Múltiples indicaciones que no son aceptadas por el código. Rechazada.

\subsection{Inspección visual artificial (IVA)}

De la inspección visual se obtuvieron las imágenes de cada una de las probetas para ser procesadas por el programa previamente entrenado, en el que se detallaron las distintas indicaciones de los cordones de soldadura de la cara de la unión y de la raíz en imágenes binarias en el cual fueron separadas por tipo de discontinuidad identificada por el programa, y por las que después se agrupan y se presentan todas las indicaciones en una sola imagen, identificando las discontinuidades con los siguientes colores:

- Verde: Contorno del cordón de soldadura.

-Azul oscuro: Salpicadura.

- Rojo: Falta de continuidad y contorno falta de penetración.

- Azul claro: Contorno exceso de penetración y dentro del cordón identifica porosidad.

Teniendo en cuenta el criterio de entrenamiento del software se obtuvieron como resultados las siguientes apreciaciones: 
- Junta soldada P25: cara de la unión que presenta un cordón de contorno regular y aceptable, sin presencia de discontinuidades. Raíz de soldadura con penetración completa, sin presencia de discontinuidades. Unión de soldadura aceptable.

- Junta soldada P95: cara de la unión que presenta un contorno irregular del cordón de soldadura, identifica indicaciones de salpicaduras. En raíz de soldadura se identifica falta de penetración. Unión de soldadura rechazada.

- Junta soldada P33: cara de la unión que presenta un cordón de contorno regular y aceptable, sin presencia de discontinuidades. En raíz de soldadura se identifica exceso de penetración. Unión de soldadura rechazada.

- Junta soldada P46: cara de la unión que presenta un cordón de contorno regular, en el cual se identifica un gran número de poros a lo largo del cordón de soldadura, al igual salpicadura en exceso. Raíz de soldadura con penetración completa, sin presencia de discontinuidades. Unión de soldadura rechazada.

- Junta soldada P99: cara de la unión que presenta un cordón de contorno irregular, en el cual se identifica falta de continuidad y poca salpicadura. En raíz de soldadura se identifica falta de penetración. Unión de soldadura rechazada.

- Junta soldada P101: múltiples indicaciones que no son aceptadas por el código. Cara de la unión que presenta un cordón de contorno irregular, en el cual se identifica un gran número de poros a lo largo del cordón, falta de continuidad, y salpicadura moderada. Raíz de soldadura se identifica falta de penetración y exceso de penetración. Unión de soldadura rechazada.
- En el análisis de la probeta A (P25), ambos métodos de inspección no identifican discontinuidades y se obtiene un resultado favorable de aceptación de la probeta. Los 2 métodos brindan resultados de identificaciones iguales y confiables.

- En el análisis de la probeta B (P95), por los métodos de IV e IVA se logra identificar la falta de penetración en la raíz, es igual y en la misma posición. Para las salpicaduras el método IVA se identifica menos cantidad de la que realmente se pude observar realizando la inspección visual. La probeta tiene un resultado de rechazo debido a la falta de penetración que es un defecto que no acepta el código.

- En el análisis de la probeta C (P33), los resultados de la IV logran identificar una mayor longitud en el exceso de penetración en el cordón de raíz respecto al que se logra identificar con IVA, cuando el cordón excede una altura mayor a $3 \mathrm{~mm}$ no es aceptable. Para el caso de la IVA el exceso de penetración se obtuvo por el ancho del cordón, ya que su análisis es en $2 \mathrm{D}$, por lo cual esta discontinuidad puede llegar a ser mejor evaluada en $3 \mathrm{D}$, ya que para definir si esta discontinuidad es o no aceptable es la altura del cordón.

- En el análisis de la probeta D (P46), ambos métodos identifican las indicaciones de porosidad y salpicadura que se presentan y que estos son excesivos, se destaca la IVA en la identificación de los poros ya que con este método se logran resaltar más a pesar de que algunos pueden ser muy pequeños y que por medio de IV se necesitaría una lupa para observarlos bien. Al presentarse muchos poros a lo largo del cordón y que su suma llega a exceder 3/8in en pulgada lineal esta es rechazada.

Tabla 3. Comparativa entre la inspección visual y la inspección por visión artificial entorno al reconocimiento de discontinuidades en la soldadura.

\begin{tabular}{|c|c|c|c|c|c|c|c|c|c|c|c|c|}
\hline \multirow{2}{*}{ Probeta } & \multicolumn{2}{|c|}{$P$} & \multicolumn{2}{|c|}{$F C$} & \multicolumn{2}{|c|}{$S A$} & \multicolumn{2}{|c|}{$F P$} & \multicolumn{2}{|c|}{$E P$} & \multicolumn{2}{|c|}{ Resultado } \\
\hline & $I V$ & $I V A$ & $I V$ & $I V A$ & $I V$ & $I V A$ & $I V$ & $I V A$ & $I V$ & $I V A$ & $I V$ & $I V A$ \\
\hline P25 & NO & NO & NO & NO & $\mathrm{NO}$ & NO & NO & NO & $\mathrm{NO}$ & NO & $\underline{\mathbf{A}}$ & $\underline{\underline{\mathrm{A}}}$ \\
\hline P33 & $\mathrm{NO}$ & $\mathrm{NO}$ & NO & $\mathrm{NO}$ & $\mathrm{NO}$ & $\mathrm{NO}$ & NO & $\mathrm{NO}$ & $\mathrm{NO}$ & NO & $\underline{\underline{R}}$ & $\underline{\mathbf{R}}$ \\
\hline P46 & SI & SI & $\mathrm{NO}$ & $\mathrm{NO}$ & SI & SI & $\mathrm{NO}$ & $\mathrm{NO}$ & $\mathrm{NO}$ & NO & $\underline{\underline{\mathbf{R}}}$ & $\underline{\underline{\mathbf{R}}}$ \\
\hline P95 & $\mathrm{NO}$ & $\mathrm{NO}$ & $\mathrm{NO}$ & $\mathrm{NO}$ & SI & SI & SI & SI & $\mathrm{NO}$ & $\mathrm{NO}$ & $\underline{\underline{\mathbf{R}}}$ & $\underline{\underline{\mathbf{R}}}$ \\
\hline P99 & NO & $\mathrm{NO}$ & SI & SI & $\mathrm{NO}$ & SI & SI & SI & $\mathrm{NO}$ & NO & $\underline{\underline{\mathbf{R}}}$ & $\underline{\mathbf{R}}$ \\
\hline P101 & SI & SI & SI & SI & SI & SI & SI & SI & SI & SI & $\underline{\underline{\mathbf{R}}}$ & $\underline{\underline{\mathbf{R}}}$ \\
\hline
\end{tabular}

Fuente: Los autores. 

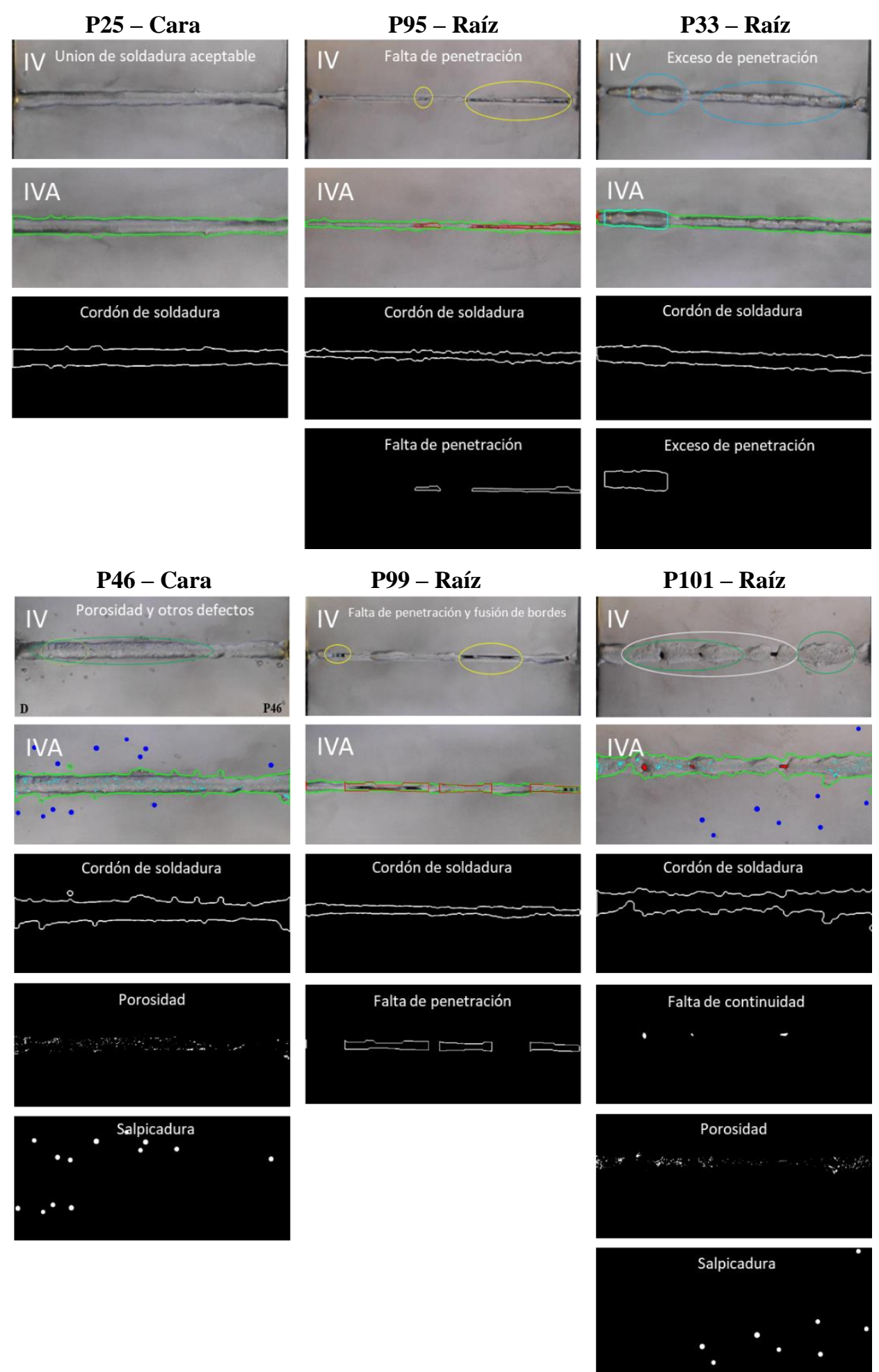

Figura 5. Análisis comparativo entre las técnicas de inspección visual (IV) e inspección por visión artificial (IVA). Fuente: Los autores.

- En el análisis de la probeta $\mathbf{E}$ (P99), ambos métodos de inspección identifican las indicaciones de falta de penetración, la falta de continuidad y un cordón irregular de mal aspecto. En el caso de la IVA este identifica la poca salpicadura presente en el metal base, y que por el método de IV no fue relacionado. La probeta de soldadura es rechazada al presentar varios defectos como falta de penetración y falta de continuidad, por esas razones no son aceptadas por el código AWS D1.6.

- En el análisis de la probeta F (P101), ambos métodos de inspección identifican las múltiples indicaciones presentes como: poros a lo largo del cordón, falta de penetración y exceso de penetración en la raíz, salpicadura moderada, falta de 
continuidad y un cordón irregular de mal aspecto. Por lo cual la probeta es rechazada. Para ambos métodos los resultados son similares y confiables en la identificación de las discontinuidades.

Analizando los resultados de la inspección se observa que los criterios brindados por ambos métodos son similares, debido a que logran dar aceptación a la probeta que presenta un buen acabado del cordón de soldadura y rechazan las otras 5 por presentar discontinuidades. La Tabla 3 muestra el resumen de los resultados de la inspección visual y el total de detecciones realizadas por el software. El software buscó la presencia de cinco discontinuidades en seis probetas, realizando un total de 30 detecciones, de las cuales 29 concordaron con la evaluación del inspector, y se presentó una discrepancia en la presencia de salpicaduras en la probeta P99, donde se verificó que había presencia de las mismas. Evidenciando mayor exactitud del análisis automático frente al concepto visual humano. En general, este error pudo provenir de la fatiga, capacidad visual del inspector o ser conservador en la inspección.

Finalmente, la aplicación de inspección artificial por procesamiento de imágenes en su primera fase de desarrollo de reconocimiento es capaz de identificar las discontinuidades presentes en una soldadura y brindar resultados similares y confiables como la inspección visual realizada por el hombre.

\section{Conclusiones}

La implementación de parámetros operativos correctos evidenció que los resultados de las juntas soldadas son positivos, obteniendo así: soldaduras sanas y aceptables según la norma aplicada. Paralelo a esto se evidenció que cuando modificamos algunas de estas variables y parámetros aparecen las discontinuidades, generando así soldaduras permeadas de defectos y rechazadas. Lo anterior conlleva a determinar que los parámetros inadecuados y no tener la habilidad necesaria ocasionan altos niveles de discontinuidades $y$ rechazo permanente de juntas.

La inspección por procesamiento de imágenes proporcionó la identificación de las salpicaduras, falta de continuidad y falta de penetración, las cuales fueron reconocidas y detalladas de forma clara. Cabe destacar que la inspección visual mediante visión artificial (IVA) presentó un gran alcance para la identificación de poros, que por ser algunos muy pequeños para el método de inspección visual se dificultó la identificación de estos.

El análisis de los resultados de comparación por ambos métodos de inspección, los criterios de aceptación y rechazo coincidieron para todas las probetas. Adicionalmente, se observó que en 5 de las 6 probetas examinadas las indicaciones encontradas fueron las mismas tanto por inspección visual como por procesamiento de imágenes. En uno de los casos la inspección visual artificial identificó la salpicadura que para este caso no relacionó la inspección visual, obteniendo una probabilidad de fracaso del $0.2 \%$, por falla en la inspección visual.

\section{Referencias}

AWS. (2007). Structural Welding Code - Stainless Steel. AWS D1.6/D1.6M. EE. UU: American National Standard.

Carbajal, C. (2017). Metodología para inspección visual remota en juntas soldadas de tuberías de acero inoxidable mayores a 4 " de diámetro $v$ con espesores hasta $3 \mathrm{~mm}$ empleando el videoscopio lenox modelo pvs. Lima: Pontificia Universidad Católica del Perú.

Castro, J., \& Serrano, C. (2016). Influencia del tamaño de las discontinuidades en las propiedades mecánicas de las uniones soldadas bajo la norma API 1104. Quito: Escuela politécnica nacional.

COGNEX. (2018). Introducción a la visión artificial, una guía para la automatización de procesos y mejorar la calidad. Estados Unidos : Iluminado. No. IMVWP-2018-0331-ES.

Gámez, L. (2017). Análisis de la soldabilidad de aceros inoxidables austeníticos unidos mediante el proceso GMAW. Coahuila: Corporación Mexicana de Investigación de Materiales.

Hurtado, J., \& Vaca, T. (2021). Optimización del proceso de soldadura GMAW sobre superficies planas con el diseño y construcción de un equipo automático portátil de suelda e inspección 
visual, mediante visión artificial para el laboratorio de soldadura en ESPE, Latacunga. Latacunga: Universidad de las Fuerzas Armadas.

Indura: Tecnología a su servicio . (2010). Manual de aceros inoxidables. Chile : $2 M$ Impresores Ltda.

Loja, C. (2015). Inspección de soldadura Mig-Mag de piezas metálicas, visión artificial y procesamiento de imágenes. Cuenca: Universidad Técnica Salesiana. 